\title{
Selecting the appropriate public transportation system to access the Sari International Airport by fuzzy decision making
}

\author{
GholamAli Shafabakhsh • Mansour Hadjihoseinlou • \\ Seyed Ali Taghizadeh
}

Received: 22 April 2013 / Accepted: 3 December 2013 / Published online: 20 December 2013

(C) The Author(s) 2013. This article is published with open access at SpringerLink.com

\begin{abstract}
Introduction Air travel is the fastest way for transporting goods and human; therefore, the airports are vital parts of transportation industry. Since airports are considered as tourism gates, they have a great influence on tourism sector and sub-domains economic. Sari is a city with many tourist attractions and has been known as the center of tourism in the north of Iran. Unfortunately because of the relatively long distance between Sari International Airport and the city and suburbs besides the lack of the proper access to these areas, tourists and businessmen didn't consider it as beginning or ending point of their travels, so Sari International Airport missed its deserving air traffic. The goal of this research is to find the appropriate public transportation system amongst options to access this airport. This is the first time that the presented method is being used for selecting one public transportation system to access airport.

Method This research has been done by using paired comparison for effective parameters of this selection by the decision makers, and determining the weight of parameters by using the Mikhailov method in fuzzy analytical hierarchy process. Conclusion Finally the train system was proposed as the most appropriate public transportation system by using TOPSIS technique.
\end{abstract}

Keywords Airport accessibility $\cdot$ Public transportation systems $\cdot$ Fuzzy analytical hierarchy process $\cdot$ TOPSIS

G. Shafabakhsh $\cdot$ S. A. Taghizadeh $(\bowtie)$

Faculty of Civil Engineering, Semnan University, Semnan, Iran

e-mail: a.taghizadeh@sun.semnan.ac.ir

G. Shafabakhsh

e-mail: Shafabakhsh@semnan.ac.ir

M. Hadjihoseinlou

Faculty of Civil Engineering, K.N.Toosi University of Technology,

Tehran, Iran

e-mail: Mansour@kntu.ac.ir

\section{Introduction}

Airports are essential resources for contemporary living. They play a major role in transporting people and goods around the world. Furthermore, airports connect air travelers with other modes of transportation. Therefore, an airport can be seen as a node that is connected to ground travel. Because air and ground systems are interrelated, they affect each other [1]. The goal of this research is to take effective steps in improving the airport's air traffic by considering the tourist attraction potential in Sari International Airport and the difficulties to access this airport for passengers, for either business and nonbusiness travels and also airport's employees and staffs. This made us to have a look at incorporated solutions in important airports around the world and the current scientific methodologies in this area to propose an appropriate public transportation system considering airport's present conditions and take a glance at the future to access this airport. Since public transportation mode choice is a cumbersome and time-consuming process with multiple constraints. This paper presents a simplified methodology for selecting an appropriate public transportation system by using an integrated multiple criteria decision making ${ }^{1}$ process.

\section{Literature review}

Harvey (1986) investigated the factors that influencing the choice of airport access mode for travelers who living in the San Francisco Bay Area. He separated travelers into two groups of business and non-business travelers, and concluded that access time and access cost are the most important parameters influencing airport access mode choice [2]. Pels et al. (2001) investigated the relationship between non-business and

${ }^{1} \mathrm{MCDM}$ 
Fig. 1 Effective criteria in choosing the appropriate transportation system

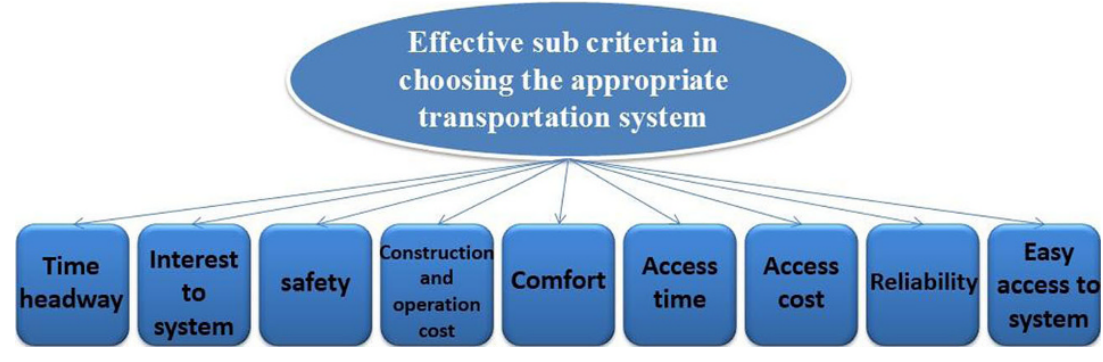

business travelers on the choice of access mode. They found that importance of access time for a business trips is higher than for non-business trips [3]. Chebli et al. (2003) investigated the effects of comfort that supplied by different access modes on mode choice behavior [4]. Hess (2004) developed a model to analyze a passenger's access mode choice to airport. He showed that ticket price was not an important parameter for business travelers [5]. Tam et al. (2006) investigated the choice of access mode to Hong Kong International Airport and found that service performance like comfort is one of the important factor on access mode choice to airport. They also showed the reliability of transportation mode is one of the most important factor on airport access mode choice. Reliability to transportation mode is the difference between the actual time and the expected time of a mode to get to the airport [6]. Jou et al. (2011) by investigating and evaluating present transportation systems in Taiwan International Airport and the influence of the construction of new transportation system (MRT) on the behavior of the passengers in choosing the type of the system, have demonstrated that the time spent inside the vehicle and outside the vehicle is one of the important parameters in selecting the mode of the transportation system for getting to the airport. The total saved time and a calm and friendly environment are another important parameters for choosing a system [7]. Alhussein (2011) interpreted the mode choice to access King Khaled Airport of Saudi Arabia and by studying different types of present transportation systems stated that parameters such as time, access cost, reliability, and comfort are the most important parameters in choosing the transportation modes by the passengers [1]. Tsamboulas et al. (2012) studied the Athens International Airport employees travels to and back this airport through stated and revealed performance data and by interpreting the present conditions, demonstrated that time and cost of the travel and the salary of the employees are the main parameters in choosing the travel mode, and also demonstrated that metro and train with reasonable ticket price and travel time can attract a big share of the employees travels [8]. Meyer et al. (1984) in addition to considering economical parameters such as construction costs, operation costs, maintenance costs and travel costs of different public transportation modes, has also investigated these systems from viewpoints of services, travel time, capacity, and performance characteristics [9]. Zhi-Ping Fan et al.
(2001) have investigated the multi criteria decision by information and data, and prioritized the options. One new view for solving the MADM problem where the decision maker states his/her priorities fuzzily has been proposed. For reflecting the decision maker's prioritizing data, one optimization model is being created to estimate the weight of criteria and then select the most appropriate option [10]. Gumus (2009) by considering this fact that hazardous waste may threaten the health of humans and the environment, and its safe transport is important, mentioned that choosing the right transportation company would be one of the important problems of hazardous waste generators. This researcher based on the two step method for evaluating and choosing the transportation companies of hazardous waste, did his research by using Fuzzy-AHP and TOPSIS methods [11]. Bashiri et al. (2011) based on the fact that managers in constructing parameterizes are facing numerous problems such as choosing the technology of the construction of the company, choosing the strategy of maintenance of the parameter, relocation of machines, investigation of the quality of performance, choosing the seller and etc., stated that the multi criteria decision making is one of the tools for decision making and can help the managers in making accurate decisions [12]. Shelton et al. (2009) showed Transportation projects prioritization is a cumbersome and time consuming process. They investigated a simplified methodology for ranking transportation projects by using an integrated multiple criteria decision making process for prioritizing

Determining the criteria

Inquiry by questionnaire

Making relative preference matrix of criteria in fuzzy environment

Calculation of the weight of criteria by using Mikhailov method

Calculation of the compatibility of questionnaires

Assessing the alternatives

Final prioritizing of the systems based on TOPSIS method

Fig. 2 Decision making process 


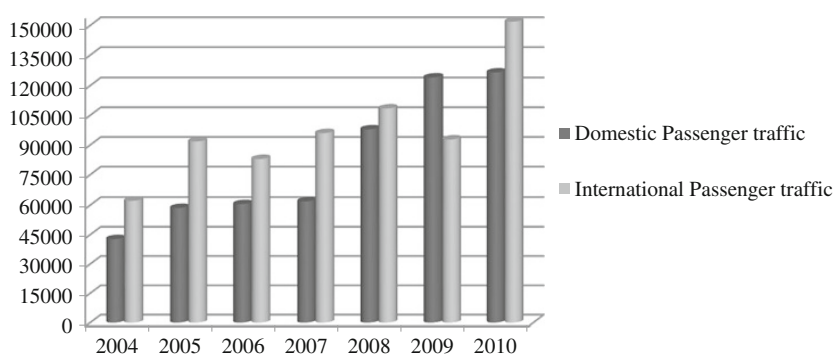

Fig. 3 Number of passengers of Sari International Airport 2004-2010

transportation projects when there are groups of decision makers with multiple opinions and biases [13].

Regarding the investigations on different articles, the main and principle parameters in choosing the proper transportation system can be represented by nine criteria as in Fig. 1.

\section{Research method}

This research was carried out by creating a questionnaire, paired comparison of the criteria by using the process of fuzzy hierarchical process by 3 groups of decision makers involving transportation experts, airport operators and employees beside passengers inhabited in city of Sari that have used this airport as a point of their travel at least 5 times, and the effective criteria are weighted by Mikhailov method in choosing the appropriate public transportation system to access the airport after paired comparison in fuzzy environment. Those questionnaires that are not within the compatibility value are omitted from the decision making process. At the end, prioritized options and the suitable option are determined and are proposed by using TOPSIS method by experts. TOPSIS is one of the multiple criteria decision making methods that popular between decision makers because of its simplicity and accuracy. TOPSIS ranks alternatives according to an algorithmic procedure. Alternatives are sorted in decreasing order of Closeness Coefficient which is calculated with respect to distance of a given alternative from both positive and negative ideal solution concurrently [14]. But TOPSIS has been criticized by its disadvantages, such as: (1) the Euclidean distance

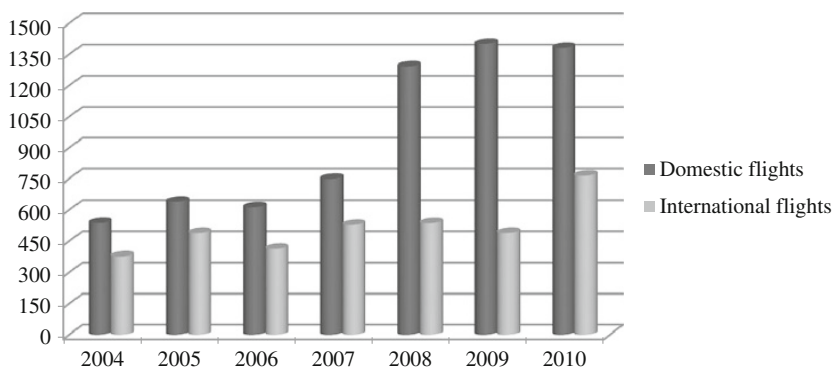

Fig. 4 Number of flights in Sari International Airport 2004-2010

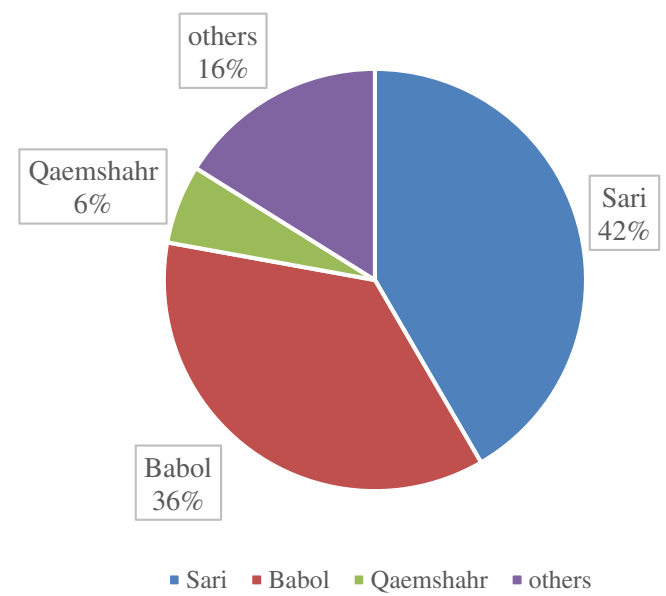

Fig. 5 The volume ratio of passengers from cities around Sari airport

algorithm is used in principle which doesn't consider the correlation of attributes; (2) the method fixes weight coefficients using expert investigation method which has subjectivity; (3) It is more difficult to determine weight and keep the consistency of judgment matrix, especially when it is used with more attributes. For this reason we have used MATLAB software that made the calculation of TOPSIS method so easy. The decision making process is shown in Fig. 2.

\section{Model}

Regarding the geographical location of Sari International Airport which connected to Sari-Neka highway on the south and Goharbaran tourist road and tourist areas of Dashtenaz on the north, and also located along the Tehran-Shomal railroad, can bring it as a strategic airport in Iran. Unfortunately Sari International Airport not only doesn't handle adequate number of air traffic, also caused lots of problems for airport employees that have to travel to this airport daily, because of

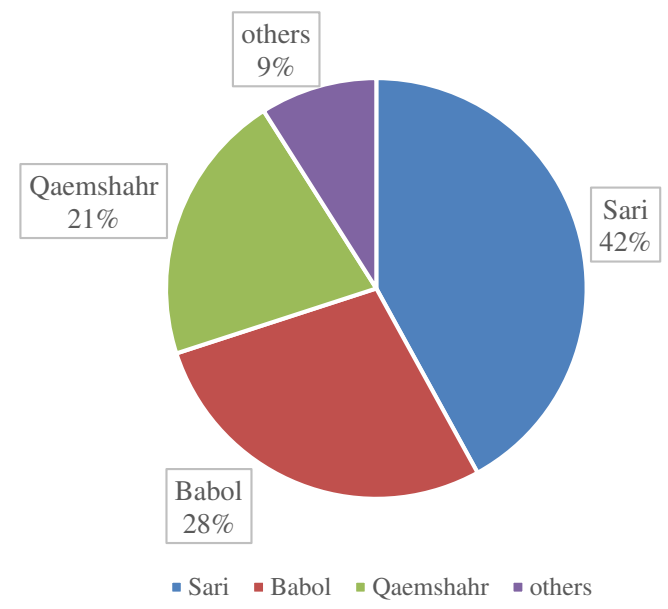

Fig. 6 The volume ratio of airport's employees divided by city 


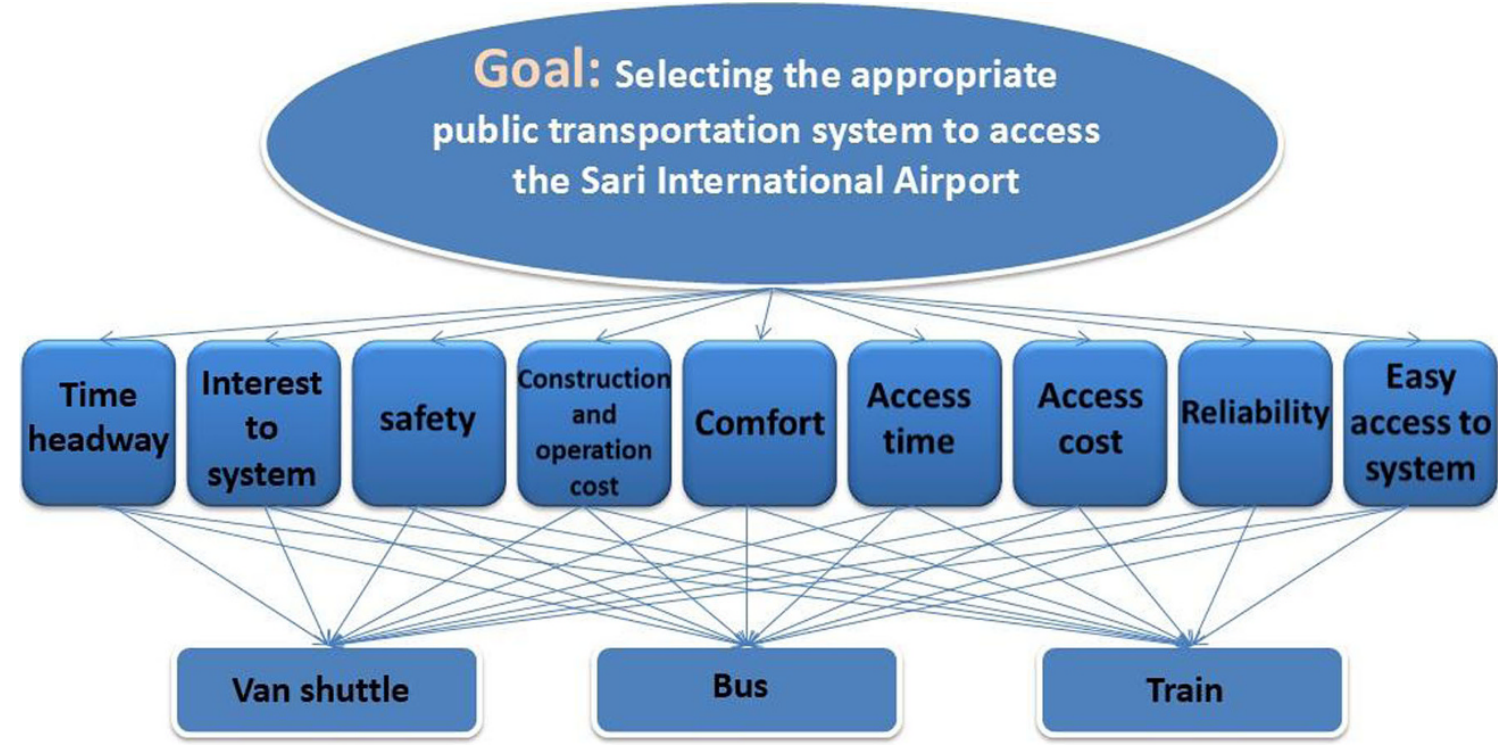

Fig. 7 Criteria and alternatives for choosing suitable transportation system

inappropriate accessibility. The only modes to access this airport are private cars and taxi.

By considering this airport conditions and present infrastructures, these modes have been proposed for Sari airport by this research: train, bus with 25 passenger capacity and van shuttle with 5 seats and a space for passengers' luggage. Since the distance between Sari International Airport and main railroad is about $1.5 \mathrm{~km}$, and with a look to todays and the future conditions of this airport, which is located in a strategic tourism, business, and military area, it is possible to consider the construction of a train station in order, accessibility to this airport and transportation of goods become easier and more probable.

Sari International Airport in 2004 to 2010 by considering the growth of global tourism, had improvement in air traffic but still is far away the deserving air traffic and number of passengers handling for Sari. The statistics of passengers and flights of Sari International Airport is presented in Figs. 3 and 4.

Inquiries in Sari International Airport show that $78 \%$ of the passengers would like to use a public transportation system to access the airport. As Sari International Airport doesn't have any public transportation system to access it, this research is done based on the hypothesis that such public transportation service is going to be built. The volume ratio of passengers shown in Fig. 5, has been determined by 250 inquiries in the airport, from the passengers, and data of airport employees which are presented in Fig. 6, achieved by the data which were provided to us by the airport authority. As can be seen, the majority of the passengers are Sari inhabitants.
Table 1 Sample completed questionnaire

\begin{tabular}{|c|c|c|c|c|c|}
\hline Number & Criteria & & Criteria & & Importance \\
\hline 1 & Easy access to system & $\square$ & Reliability & घ & $\mathrm{B}$ \\
\hline 2 & Easy access to system & $\square$ & Access cost & - & $\mathrm{D}$ \\
\hline 3 & Easy access to system & $\square$ & Access time & घ & $\mathrm{D}$ \\
\hline 4 & Easy access to system & $\square$ & Comfort & a & $\mathrm{C}$ \\
\hline 5 & Easy access to system & घ & Construction and operation cost & $\square$ & $\mathrm{D}$ \\
\hline 6 & Easy access to system & $\square$ & Safety & a & $\mathrm{D}$ \\
\hline 7 & Easy access to system & - & Interest to system & $\square$ & $\mathrm{C}$ \\
\hline 8 & Easy access to system & $\square$ & Time headway & $\square$ & $\mathrm{B}$ \\
\hline 9 & Reliability & घ & Access cost & $\square$ & $\mathrm{B}$ \\
\hline 10 & Reliability & $\square$ & Access time & घ & $\mathrm{B}$ \\
\hline$\ldots$ & $\ldots \ldots$ & $\square$ & $\ldots \ldots$ & $\square$ & $\ldots$ \\
\hline 36 & Interest to system & $\square$ & Time headway & - & $\mathrm{B}$ \\
\hline
\end{tabular}


Table 2 Verbal scales for stating the degree of importance

\begin{tabular}{llll}
\hline Importance & $\begin{array}{l}\text { Verbal scales for stating } \\
\text { the degree of importance }\end{array}$ & $\begin{array}{l}\text { Triangle } \\
\text { fuzzy } \\
\text { numbers }\end{array}$ & $\begin{array}{l}\text { Reverse triangle } \\
\text { fuzzy numbers }\end{array}$ \\
\hline $\mathrm{A}$ & $\begin{array}{l}\text { Equivalent important (EI) } \\
\text { Weak more important } \\
\text { (WMI) }\end{array}$ & $\begin{array}{l}(1 / 2,1,3 / 2) \\
(1,3 / 2,2)\end{array}$ & $(2 / 3,1,2)$ \\
C & $\begin{array}{c}\text { Strong more important } \\
\text { (SMI) }\end{array}$ & $(3 / 2,2,5 / 2)$ & $(2 / 5,1 / 2,2 / 3)$ \\
$\mathrm{D}$ & $\begin{array}{c}\text { Very strong more } \\
\text { important (VSMI) }\end{array}$ & $(2,5 / 2,3)$ & $(1 / 3,2 / 5,1 / 2)$ \\
$\mathrm{E}$ & $\begin{array}{c}\text { Absolute more important } \\
\text { (AMI) }\end{array}$ & $(5 / 2,3,7 / 2)$ & $(2 / 7,1 / 3,2 / 5)$ \\
& & & \\
\hline
\end{tabular}

\subsection{Creating the hierarchy of criteria and alternatives}

The problem and the goal of decision making is being created in a hierarchical process by the decision parameters which related to each other. The decision parameters involve decision making criteria and decision options that showed on Fig. 7. The criteria and decision options have been selected by researchers and present conditions of Sari International Airport with regard to previous studies.

\subsection{Preparing the questionnaires and performing paired} comparison

By considering the criteria, a questionnaire for performing paired judgment between the criteria was designed. Then the comparison between criteria was performed based on the importance of the each criteria by performing paired comparison. The decision makers actually have to complete the matrices that show relative preference of criteria against each other. But for the ease of this work, they only filled the questionnaire by determining the relative importance between criteria, so the criteria was compared two by two verbally. A sample of completed questionnaire could be seen in Table 1 . Also, the degree of relative importance as shown in Table 2 is chosen based on the fuzzy numbers presented in Fig. 8.

Then by assigning its numerical equivalent in fuzzy set, the relative preference matrix of criteria was formed. In Table 3 a

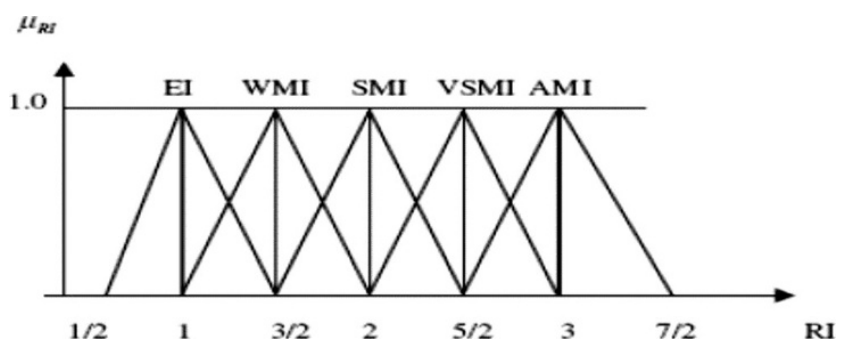

Fig. 8 Verbal scale for determining the degree of importance

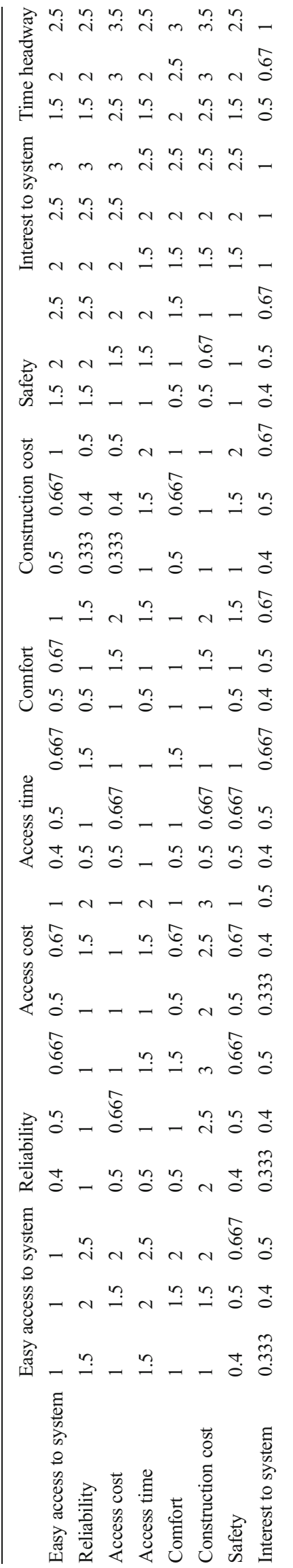


Table 4 Profile information of participants in questionnaires

\begin{tabular}{ll}
\hline University professor at transportation engineering & 5 \\
Ph.D. student at transportation engineering & 4 \\
MSc on transportation engineering & 11 \\
Airport specialists and authorities & 13 \\
Employees and passengers inhabited in city of Sari that have used & 28 \\
Sari International Airport as a point of their travel at least 5 times &
\end{tabular}

sample of this formation is shown. The profile information of participants in questionnaires is shown in Table 4 too.

\subsection{Calculation the weight of criteria}

According to Mikhailov model, the upper and lower limit of the fuzzy numbers is calculated in paired comparison between criteria, and with regard to the present deviation, the weight of each parameter or criterion would be achieved. For every compatible questionnaire, we would have one weight for each of the criteria. Every questionnaire underwent this process and then the arithmetic average of resulted weights in each of the three groups of decision maker was calculated and then the arithmetic average of all three groups in the form of weight vector $\mathrm{W}_{\mathrm{T}}$ was calculated. The comparison of the resulted weights is presented in Fig. 9.

$$
\begin{aligned}
& \mathrm{W}_{\mathrm{T}}=\left\{\begin{array}{lllll}
0.10862, & 0.12735, & 0.11459, & 0.11851, & 0.10689
\end{array}\right. \\
& 0.07690,0.18928,0.07830,0.07951\}
\end{aligned}
$$

It is noticeable that the safety is the most important parameter from the view of transportation experts, airport specialists and authorities, passengers and employees, and the least important parameter is the construction and operating costs.

\subsection{Calculation of the compatibility of questionnaires}

All the calculations related to hierarchical analysis process based on judgment of decision makers who was stated in a
Table 5 The compatibility ratio in sample questionnaire

\begin{tabular}{llll}
\hline$\alpha$ & $\lambda$ & $\alpha$ & $\lambda$ \\
\hline 0 & 1.0118442 & 0.6 & 0.9955634 \\
0.1 & 1.0090460 & 0.7 & 0.9929570 \\
0.2 & 1.0062838 & 0.8 & 0.9903769 \\
0.3 & 1.0035564 & 0.9 & 0.9978222 \\
0.4 & 1.0008616 & 1 & 0.9949676 \\
0.5 & 0.9981976 & & \\
\hline
\end{tabular}

paired matrix template. Any type of error and incompatibility in comparisons and determining the importance of criteria effects the final results. The compatibility value, is a tool which determines the compatibility and shows how much the resulted weights are reliable. Mikhailov stated that it is possible to use $\lambda$ as a proper criteria for measuring the compatibility of comparisons and a $\lambda$ approximately more than 1 , shows the compatibility value of comparisons [15].

The compatibility value for the completed sample questionnaire for $0<\alpha<1$ in Mikhailov's model, is presented in Table 5.

Since for values of $\alpha>0.4$, the compatibility ratio was more than $1(\lambda>1)$, then the average value of $\alpha=2$ for $0<\alpha<$ 0.4 , is a suitable factor for calculating the upper and lower bounds in Mikhailov model for calculating weight of criteria. From the 61 questionnaires, 14 of them were considered incompatible, which means for all value of $\alpha$, the value of $\lambda$ was less than 1 , which were removed from the prioritizing process.

\subsection{Final prioritizing of the systems based on TOPSIS method}

Based on the filled questionnaires and paired fuzzy comparison of criteria, and after receiving the weights of the criteria, we can prioritize the transportation system according to the effect of each parameter or criteria in any type of transportation modes. The questionnaire II, was filled only by the
Fig. 9 The resulted weights from questionnaires

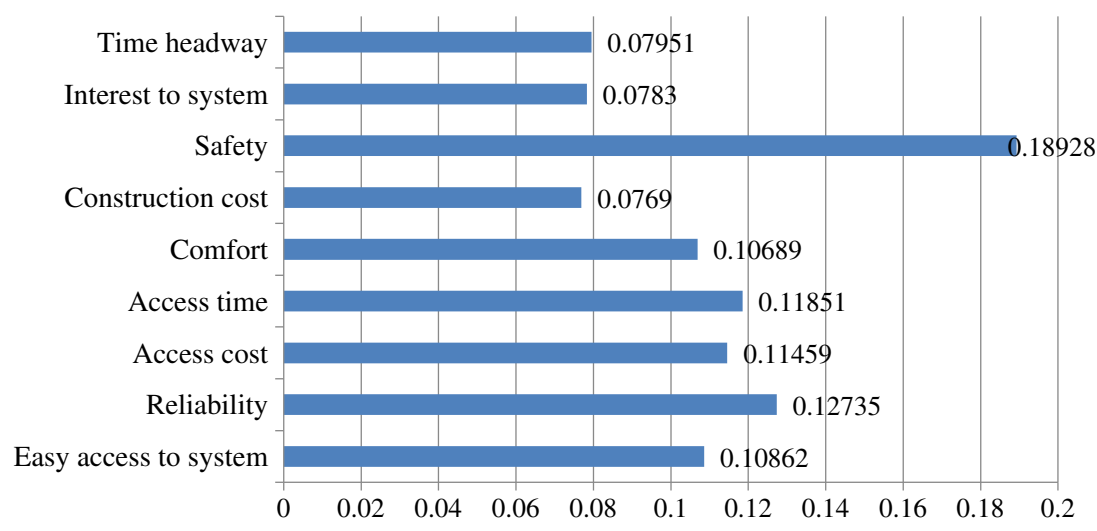


Table 6 Filled sample of questionnaire II

\begin{tabular}{llll}
\hline System/Criteria & Train & Bus & Van Shuttle \\
\hline Easy access to system & 50 & 60 & 70 \\
Reliability & 90 & 60 & 70 \\
Access cost & 20 & 40 & 65 \\
Access time & 40 & 70 & 50 \\
Comfort & 40 & 60 & 80 \\
Construction and operating costs & 40 & 15 & 10 \\
Safety & 90 & 50 & 30 \\
Interest to system & 45 & 60 & 70 \\
Time headway & 90 & 55 & 35 \\
\hline
\end{tabular}

$\mathrm{DM}=\left[\begin{array}{ccccccccc}80 & 74.17 & 30 & 50 & 55 & 71.67 & 90.83 & 70.83 & 87.5 \\ 62.5 & 58.33 & 50.83 & 73.33 & 53.33 & 42.5 & 67.5 & 63.33 & 60 \\ 82.5 & 72.5 & 77.5 & 60.83 & 80 & 30 & 51.67 & 81.67 & 75.83\end{array}\right]$

\subsection{Performing TOPSIS method}

Step I: By using $n_{i j}=\frac{r_{i j}}{\sqrt{\sum^{m}}}$ equation, normalized matrix

$$
\sqrt{\sum_{i=1} r_{i j}^{2}}
$$

of $\mathrm{N}_{\mathrm{DM}}$ is calculated.

$\mathrm{N}_{\text {DM }}=\left[\begin{array}{lllllllll}0.612 & 0.623 & 0.308 & 0.465 & 0.497 & 0.809 & 0.730 & 0.565 & 0.671 \\ 0.478 & 0.490 & 0.522 & 0.682 & 0.481 & 0.480 & 0.543 & 0.505 & 0.460 \\ 0.631 & 0.609 & 0.796 & 0.565 & 0.722 & 0.339 & 0.415 & 0.652 & 0.581\end{array}\right]$

Step II: Calculating the normalized harmonic matrix (V)

$\mathrm{V}=\mathrm{N}_{\mathrm{DM}} \times \mathrm{W}_{\mathrm{T}}=\left[\begin{array}{lllllllll}0.0665 & 0.0793 & 0.0353 & 0.0551 & 0.0531 & 0.0621 & 0.1381 & 0.0442 & 0.0534 \\ 0.0519 & 0.0624 & 0.0598 & 0.0808 & 0.0514 & 0.0369 & 0.1028 & 0.0395 & 0.0366 \\ 0.0685 & 0.0776 & 0.0912 & 0.0670 & 0.0771 & 0.0261 & 0.0786 & 0.0511 & 0.0462\end{array}\right]$

Step III: Determining the positive ideal result and negative ideal result.

$$
\begin{aligned}
& A^{+}=\left\{\left(\max _{i} v_{i j} \mid j \in J\right),\left(\min _{i} v_{i j} \mid j \in J^{\prime}\right) \mid i=1,2, \ldots, m\right\}=\left\{\max _{i} v_{i 1}, \max _{i} v_{i 2}, \min v_{i 3}, \min _{i} v_{i 4}, \max _{i} v_{i 5}, \min v_{\mathrm{i} 6}, \max v_{\mathrm{i} 7}, \max v_{\mathrm{i} 8}, \min v_{\mathrm{i} 9}\right\} \\
& =\left\{\begin{array}{lllll}
0.0685 & 0.0793, & 0.0353,0.0551, & 0.0771,0.0261, & 0.1381,0.0511,0.0366
\end{array}\right. \\
& A^{-}=\left\{\left(\min _{i} v_{i j} \mid j \in J\right),\left(\max _{i} v_{i j} \mid j \in J^{\prime}\right) \mid i=1,2, \ldots, m\right\}=\left\{\min _{i} v_{i 1}, \min _{i} v_{i 2}, \max _{i} v_{i 3}, \max _{i} v_{i 4}, \min _{i} v_{i 5}, \max v_{\mathrm{i} 6}, \min v_{\mathrm{i} 7}, \min v_{\mathrm{i} 8}, \max v_{\mathrm{i} 9}\right\}
\end{aligned}
$$

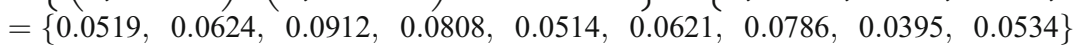

experts in transportation. They choose a number between 100 according to the effect of the each criteria on transportation modes. A sample of filled question-

The arithmetic average of experts' views was calculated, a matrix was resulted from their views which shows the decision making matrix (DM). Then by using TOPSIS method and with the present matrix and the weight vector of criteria, prioritizing was performed. It must be considered that the criteria of travel cost, travel time, construction costs, operation costs, and time headway are negative parameters which were incorporated in TOPSIS model. 
Table 7 The difference for positive and negative ideal result

\begin{tabular}{lll}
\hline Alternative & $\begin{array}{l}\text { Relative closeness to } \\
\text { the right ideal solution }\end{array}$ & $\begin{array}{l}\text { Relative closeness to } \\
\text { the right ideal solution }\end{array}$ \\
\hline Train & $d_{1}^{+}=0.025709$ & $\mathrm{~d}_{1}^{-}=0.069037$ \\
Bus & $\mathrm{d}_{2}^{+}=0.051321$ & $d_{2}^{-}=0.032903$ \\
Van Shuttle & $d_{3}^{+}=0.060811$ & $d_{3}^{-}=0.038327$ \\
\hline
\end{tabular}

Table 8 Prioritizing the alternatives using TOPSIS method

\begin{tabular}{lll}
\hline Priority & Alternative & Relative closeness value \\
\hline 1 & Train & 0.728653 \\
2 & Bus & 0.390661 \\
3 & Van shuttle & 0.386606 \\
\hline
\end{tabular}

Step IV: Calculating the difference between each result and the positive and negative ideals

$$
\begin{aligned}
d_{1}^{+}= & \sqrt{(0.0665-0.0685)^{2}+(0.0793-0.0793)^{2}+(0.0353-0.0353)^{2}+(0.0551-0.0551)^{2}+(0.0531-0.0771)^{2}+(0.0621-0.0261)^{2}+(0.1381-0.1381)^{2}+(0.0442-0.0511)^{2}+(0.0534-0.0366)^{2}} \\
& d_{1}^{+}=0.025709 \\
\mathrm{~d}_{1}^{-}= & \sqrt{(0.0665-0.0519)^{2}+(0.0793-0.0624)^{2}+(0.0353-0.0912)^{2}+(0.0551-0.0808)^{2}+(0.0531-0.0514)^{2}+(0.0621-0.0621)^{2}+(0.1381-0.0786)^{2}+(0.0442-0.0395)^{2}+(0.0534-0.0534)^{2}} \\
& \mathrm{~d}_{1}^{-}=0.069037
\end{aligned}
$$

The difference between each option and the positive and negative solutions in presented in Table 7

Step V: Determining the relative closeness $\left(\mathrm{CL}^{*}\right)$ of each alternatives to the ideal result.

$$
c l_{1^{+}}=\frac{d_{1^{-}}}{\left(d_{1^{+}}+d_{1^{-}}\right)}=\frac{0.069037}{0.025709+0.069037}=0.728653
$$

Step VI: Prioritizing the Alternatives

Each option that has a bigger CL, would be selected. As it's presented in Table 8, train transportation system with the highest relative

Table 9 The weight of effective parameters

\begin{tabular}{lll}
\hline Number & Criteria & Weight \\
\hline 1 & Safety & 0.18928 \\
2 & Reliability & 0.12735 \\
3 & Access time & 0.11851 \\
4 & Access cost & 0.11459 \\
5 & Easy access to system & 0.10862 \\
6 & Comfort & 0.10689 \\
7 & Time headway & 0.07951 \\
8 & Interest to system & 0.07830 \\
9 & Construction costs & 0.07690 \\
\hline
\end{tabular}

closeness is the most suitable option. The next priority is bus and after that shuttle van is the best suitable alternative.

\section{Conclusion}

This article has been carried out to present a simple model for choosing a transportation system to access Sari International Airport. First the problem was identified, then effective criteria in the problem were determined and a questionnaire was produced to determine the weight of parameters in fuzzy environment. Then paired comparison was done by three groups of decision maker consist of transportation experts, airport specialists and authorities besides employees and Sari inhabitants that used this airport more than five times. The weight of parameters were calculated by Mikhailov's method. According to the results, the weights of effective parameters in choosing the appropriate transportation mode to access Sari International Airport can be presented in Table 9.

At the end, by the weights of criteria and also inquiries that was made from transportation experts for determining the influence of each criteria on each transportation systems, the transportation modes were prioritized in TOPSIS method. Among suggested alternatives, train system was chosen by using TOPSIS method as the best and most suitable alternative. 
Open Access This article is distributed under the terms of the Creative Commons Attribution License which permits any use, distribution, and reproduction in any medium, provided the original author(s) and the source are credited.

\section{References}

1. Alhussein S (2011) Analysis of ground access modes choice King Khaled International Airport, Riyadh, Saudi Arabia. J Transp Geogr 19:1361-1367

2. Harvey G (1986) Study of airport access mode choice. J Transp Eng 112(5):525-545

3. Pels E, Nijkamp P, Rietveld P (2001) Airport and airline choice in a multiple airport region: an empirical analysis for the san Francisco Bay Area. Reg Stud 35(1):1-9

4. Chebli H, Mahmassani HS (2003) Air travelers' stated preferences towards new airport landside access mode services. Annual Meeting of Transportation Research Board, Washington DC

5. Hess S (2004) A model for the joint analysis of airport, airline, and access-mode choice for passenger's departing from the San Francisco Bay area. The European Transport Conference, Strasbourg

6. Tam ML, Lam, William HK, Lo HP (2006) Modeling the effect of safety margin on air passenger behavior for ground access mode choice problems. In: 11th International Conference on Travel Behavior Research, Kyoto

7. Jou R, Hensher D, Hsu T (2011) Airport ground access mode choice behavior after the introduction of a new mode: a case study of Taoyuan International Airport in Taiwan. Transp Res E 47:371-381

8. Tsamboulas D, Evmorfopoulos AP, Moraiti P (2012) Modeling airport employees commuting mode choice. J Air Transp Manag 18:74-77

9. Meyer MD, Miller EJ (1984) Urban transportation planning, a decision oriented approach

10. Fan Z, Hu G, Xiao S (2004) A method for multiple attribute decision - making with the fuzzy preference relation on alternatives. Comput Ind Eng 46:321-327

11. Gumus AT (2009) Evaluation of hazardous waste transportation firms by using a two-step fuzzy-AHP and TOPSIS methodology. Expert Syst Appl 36:4067-4074

12. Bashiri M, Badri H (2011) A group decision making procedure for fuzzy interactive linear assignment programming. Expert Syst Appl 38:5561-5568

13. Shelton J, Medina M (2010) Prioritizing transportation projects using an integrated multiple criteria decision - making method. TRB Annual Meeting CD-ROM

14. Sadi-Nezhad S, Damghani K, Kaveh (2009) Application of a fuzzy TOPSIS method base on modified preference ratio and fuzzy distance measurement in assessment of traffic police centers performance. Appl Soft Comput 10:1028-1039

15. Zanjirchi M (2011) Fuzzy analytical hierarchy process. Saneie Shahmirzadi Press, Iran 